Modern analysis, with its interests in optical, electrical and microbiological techniques, makes very great demands on the training of its practitioners, and it was emphasized by speakers from several countries that the training of analytical chemists lags a long way behind the requirements of modern industry.

Prof. van Nieuwenburg, in his opening address to the Congress, remarked that most of the developments in modern analytical chemistry had originated in the requirements of industry, and pointed out that this was borne out by the type of papers contributed to the Congress. He commented on the high cost of modern analytical equipment and said that much of it could only be purchased by the larger industrial laboratories; even these have to make a selection from the wide range of available instruments. An opportunity for the exchange of experiences gained in different laboratories with these modern techniques, such as was offered by the Congress, was most useful, and the dissemination of information in this way might lead to a saving of both time and money that might have been spent on inappropriate or useless equipment.

Most of the lectures and papers dealt with problems arising directly from the demands of industry. Dr. E. C. Wood, in his lecture on statistical aspects of chemical analysis to Section I, discussed the methods of sampling which enable the information sought by the analyst to be obtained as economically as possible. He stressed the need for proper randomization both in sampling and in performing analyses, and gave a short account of the use of 'quality control' charts in analytical work. $\mathrm{He}$ directed attention to the possibility of estimating the standard error from the range and described a method for extracting the maximum information from analytical investigations involving the estimation of a ratio. The advantages of the 'factorial' as opposed to the 'classical' type of experimental design was demonstrated and reference made to the value of carrying out an analysis of variance when examining the experimental data. Mr. W. J. Gooderham deseribed and demonstrated his soap-film apparatus for the continuous analysis of coal gas.

Prof. E. Leclerc lectured to Section II on electrical methods of analysis. After reviewing the available methods and discussing their speed and accuracy, he described their applications in the Belgian metallurgical and petroleum industries. Prof. C. Duval spoke on automatic gravimetric analysis in inorganic chemistry and described some new polarographic procedures. Mr. E. Loeuille (Section III) discussed the possibilities and limitations of quantitative spectrographic analysis.

The lectures to Section IV were given by Prof. G. Duykaerts and by Dr. T. I. Williams on absorptiometric methods in chemical analysis and on chromatography respectively. Dr. Williams dealt with partition chromatography, the chromatography of inorganic substances, and the theory of chromatography. He described how the urgency of the Plutonium Project had stimulated work on the theory of chromatography. Dr. W. F. J. Cuthbertson lectured to Section V on recent developments in microbiological assay. $\mathrm{He}$ described the different techniques by which micro-organisms may be used for the assay of vitamins and amino-acids, and indicated possible future developments. Prof. A. G. Bertrand spoke on the determination of trace elements in plants and animals.
Dr. H. W. Thompson addressed the final session of the Congress on methods based upon infra-red and ultra-violet measurements. He reviewed the war-time achievements of infra-red analysis in the petroleum field and gave a critical survey of the available commercial instruments. Prof. P.E. Wenger summed up at the conclusion of the Congress.

A high scientific standard was maintained through. out the Congress, which was held in the pleasant rooms of the Esplanade, Utrecht's modern theatre. The Dutch organisers are to be heartily congratulated on the excellent way in which the Congress was arranged.

\section{METABOLIC ASPECTS OF CONVALESCENCE*}

$\mathrm{T}$

HE fifteenth meeting of the Conference on Metabolic Aspects of Convalescence was once again one which devoted the greater part of its deliberations to one particular topic ; on this occasion the subject was "Isotopes".

Put together in printed form, the discussions make an extremely useful review of the rapidly widening application of this comparatively new technique for the study of biological problems. Already we have been forced to revise many of our long-held beliefs regarding the nature of the metabolic processes of the body. Interpretations which provided plausible explanations of previously recorded data no longer suffice. As one member of the Conference put it, "The availability of these materials [isotopes] as tools for biological experimentation will have as profound and stimulating an effect on biological and medical science as did the discovery of the microscope". Work already completed suggests that this remark is no exaggeration.

As with all newly developed techniques, however, there are pitfalls for the unwary. In this instance, in addition to the usual initial difficulties of use and interpretation, there is the physical danger of radiation injury to the workers and assistants in the laboratories concerned. Since the hazard is an invisible one, the victim remains unaware of his injury until material damage has been done. With the present rapidity of spread in the use of radioaotive materials it is inevitable that they should sometimes be handled by individuals unaware of the danger, and the part of the Conference report which deals with the diagnosis of early radiation injury and the precautions that should be taken to prevent tissue damage should be carefully studied. A state. ment from the National Cancer Institute is included which says, inter alia, "It must be emphasised that the absorption of radiation is always connected with damage, no matter how small the dose. It must also be emphasised that radiation effect may be cumulative." This places a heavy responsibility on the directors of laboratories in which work of this nature is in progress. There must be no repetition of the sufferings of the early radiologists.

In addition to the discussion of these practical issues, there are detailed considerations on the measurement of isotopes, on the synthesis of labelled compounds, and on their use in clinical investigations and in the treatment of disease.

* Conference on Metabolic Aspects of Convalescence. Transactions of the Fifteenth Meeting, New York, 31st March, 1947. Pp. 163. (Josiah Macy, Jr. Foundation, 565 Park Avenue, New York 21.) 2.25 dollars. 
In all these the reader has the advantage-inherent in the form in which these transactions are published -of not only learning what an experimenter has to say about his work, but, in addition, seeing the comments it elicited from other keenly interested participants. The question and answer, and the pooling together of small observations which, in isolation, might seem unimportant or meaningless, encourage a clarification and building up of ideas. The contrasting styles of the different contributors also make the reading of these publications much more enjoyable than the reading of some technical journals in which the papers have been so zealously 'edited' that all trace of individual style of expression has disappeared.

The remaining topics discussed at this fifteenth meeting were mostly concerned with hormone studies, and several of the papers consisted in the presentation of further data from work which had already been reported at earlier meetings. The interdepondence of the multifarious metabolic activities which take place in the human body and the consequent folly of trying to interpret any one in isolation become more and more evident as each set of these transactions is put together.

\section{W. Grant}

\section{MECHANICAL FOAM FOR FIGHTING PETROL FIRES}

F OAM for dealing with petrol fires can be generated 4 in two ways: by chemical reaction (chemical foam), or by mechanical agitation (mechanical or air foam). Mechanical foam is largely used in Great Britain and is produced by churning up air and water with a foam-stabilizing agent, such as saponin or soap. The foam-making branch pipe is the apparatus in general use by fire services.

The use of foam appears to have been originally suggested by Laurent in 1904. $\mathrm{He}$ successfully demonstrated at St. Petersburg the use of chemical foam against burning naphtha. In 1912, the first foam fighting apparatus for fire-brigade use was introduced into Britain. By 1939 , one or two efficient foam compounds were available; but they were both expensive and made from imported materials. With the outbreak of hastilities there came the probability of a large increase in the incidence of petrol fires and also the danger of a shortage of raw materials. Consequently, at the request of the Ministry of Home Security, Research and Experiments Department, an investigation into the whole problem of suitable foaming agents for combating fires of inflammable liquids was undertaken at the Chemical Research Laboratory of the Department of Scientific and Industrial Research. The experimental team was under the leadership of Dr. N. O. Clark, who is the author of Chemical Research Report No. 6 : "A Study of Mechanically Produced Foam for Combating Petrol Fires" (London : H.M. Stationery Office. 2s. $6 d$. net), in which full details of the problem, the course of the researches and the results obtained are given.

Large-scale methods were developed which permitted a quantitative estimation of the value of foam as a fire-fighting agent, and also a laboratory technique was devised for the investigation of the physical properties of foam. The nature and proper- ties of suitable foaming agents, such as chemically broken down hoof and horn meal, or glue mixed with materials similar to soapless shampoos or chemically treated blood, were elucidated. The use of chemically treated blood-a waste material from abattoirs-as a foaming agent was discovered by the research team. This new compound had the additional advantage of a much lower viscosity than other types and so could be used without modification in R.A.F. crash tenders. It produces a high-efficiency foam for combating aircraft fires, and during the War production was devoted entirely to this particular type of foam.

On the purely scientific side, quantitative evidence was obtained in favour of Plateau's classical theory of foam stability. It would appear that the expansion property depends on the interfacial tension, air/liquid, at the appropriate age of the surface, and the rate of diffusion of the active material into the surface, and is limited by the energy-level of the method of preparation. The hydrolysed proteins are, for example, slow in diffusing into the surface of their solutions. A close relation was shown to exist between the critical shearing stress of a foam prepared from a liquid with appreciable solidity in its surface to that of the corresponding liquid surface.

For the first time, a proper scientific background to the problem has been established, and the 'figure of merit' of foam on a petrol fire can be roughly estimated, but not accurately predicted, from laboratory measurements of the properties of foam, the most important being heat resistance, expansion, and petrol resistance. There is still need for relating laboratory experimental data with those of large-scale tests.

S. WEINTROUB

\section{LINEN INDUSTRY RESEARCH ASSOCIATION}

$T$ HE report of the Council of the Linen Industry Research Association, Belfast, for the year ended September 30, 1947, states that the strengthening of the financial position of the Association, which now includes practically all the firms in the industry, has permitted the Council to proceed with the Director's plans for expansion, and the new buildings have been commenced. In addition to the large shed with a floor space of 9,800 sq. ft. for technological researches on line and tow preparing, dry spinning and weaving, which forms the main extension, the new plans include the provision of more staff amenities and facilities, extension of the testing-room and further space and equipment for research in bleaching, dyeing and finishing. Reference is made to the co-operation in research which has already flowed from the liaison service described in the last annual report. Comprehensive surveys of conditions of temperature, humidity and ventilation in wet spinning mills have brought to light many striking anomalies, and have led to suggestions by which decided improvements can often be introduced very economically into the working conditions by comparatively simple measures.

Studies in the retting of different types of straw by various methods in the large-scale retting tanks have continued, and in view of the larger differences in yield caused by variations in weather conditions during field-drying of the retted flax, attention has 